DOI: http://dx.doi.org/10.18569/tempus.v13i3.2623

\title{
Aproximação às condições de saúde bucal de catadores de materiais recicláveis cooperados em Aracaju/SE
}

\section{Approach to the oral health conditions of Aracaju/ SE cooperated recycling materials}

\section{Enfoque de las condiciones de salud oral de los materiales de reciclaje cooperados de Aracaju/SE}

Filipe de Souza Nunes

Jorge Alberto Cordón Portillo

Tiago Araújo Coelho de Souza

Lívia Maria Almeida Coelho de Souza

RESUMO: Evidencia-se que na área de saúde bucal a pobreza e a exclusão sócio sanitária tem uma das suas mais evidentes manifestações, tendo em vista que pessoas pobres, que possuem baixa escolaridade e uma menor inserção no mercado de trabalho trazem consigo marcas dentárias que são reflexo de uma realidade objetiva e uma outra subjetiva. Assim foi realizada uma descrição e analise das condições de saúde bucal dos trabalhadores cooperados evidenciando os acometimentos mais prevalentes e a opinião sobre tal situação por parte dos cooperados. A avaliação foi feita por meio de uma ficha de identificação com nome, idade, sexo, em seguida os participantes responderam um questionário que trazia perguntas relacionadas ao cotidiano dos mesmos, envolvendo temas relativos à sua rotina de trabalho, saúde geral e saúde odontológica. Pode ser observado que a maior preocupação dos trabalhadores é estar apto ao trabalho, devido à necessidade de manter o seu sustento, sendo que quadros variáveis de sintomatologia dolorosa são suportados, até o limite que se possa continuar a labuta diária. É fato evidente, que o presente estudo feito na cooperativa, observando uma fração da rotina desses trabalhadores, dentro da sua realidade e segundo o seus relatos não deve encerrar-se em si devendo, por sua vez, provocar um novo olhar, com uma característica mais analítica e com uma sensibilidade a sua realidade para que os catadores de materiais recicláveis não vivam com o descaso, tendo em vista a rotina penosa que tem de enfrentar todos os dias.

Palavras-chave: Saúde bucal, Catadores de materiais recicláveis, Cooperativas 
ABSTRACT: It is evident that in the area of oral health to poverty and social exclusion Health has one of its most obvious manifestations, given that poor people, who have lower education and lower insertion in the labor market brings with tooth marks that are reflective of an objective reality and subjective another. This paper presents a description and analysis of the oral health status of workers cooperative bouts highlighting the most prevalent and opinion about this situation on the part of members. The evaluation was made by means of a form with name, age, sex, then the participants answered a questionnaire featured questions related to daily thereof, involving issues related to routine work, general health and dental health. It can be observed that the greatest concern of employees is being able to work because of the need to maintain their livelihood, and variable frame of painful symptoms are supported, to the extent that it can continue to toil daily. It is indeed evident that the present study the cooperative observing a fraction of the routine of these workers, into your reality and according to their reports should not end in itself and should, in turn, cause a new look, with a characteristic more analytical sensitivity and your reality for the waste pickers do not live with neglect, with a view to routine painful to have to face every day.

Keywords: Oral health, Recyclable material collectors, Cooperatives

RESUMEN: Es evidente que enel área de lasalud oral, la pobreza y laexclusión social y de saludtienen una de sus manifestaciones más obvias, teniendoencuenta que las personas pobres, que tienenpocaeducación y una menor inserciónenel mercado laboral, traen consigo marcas dentales que reflejan de una realidad objetiva y una subjetiva. Por lo tanto, se realizó una descripción y análisis de las condiciones de salud bucal de lostrabajadores cooperativos, destacando lostrastornos más frecuentes y laopinión de losmiembros de la cooperativa sobre dichasituación. La evaluación se realizó mediante unformulario de identificaciónconnombre, edad, sexo, luegolos participantes respondieronuncuestionario que hacía preguntas relacionadas consu vida diaria, que involucraba temas relacionados consu rutina laboral, salud general y salud dental. Se puede observar que la principal preocupación de lostrabajadores es poder trabajar, debido a lanecesidad de mantenersu sustento, y se admitensíntomasvariables de síntomas dolorosos, hasta ellímite que puede continuar eltrabajodiario. Esunhecho evidente que el presente estudio realizado enla cooperativa, observando una fracción de la rutina de estostrabajadores, dentro de surealidad y según sus informes, no debe terminar ensímismo y, a su vez, provocar una nueva mirada, con una característica más analítico y sensible a surealidad para que losrecolectores de materialesreciclables no vivancon negligencia, dada la dolorosa rutina que tienen que enfrentar todos losdías.

\section{INTRODUÇÃO}

O processo de globalização da economia tem provocado mudanças no mundo e nas relações de trabalho o que, por conseguinte ocasiona importantes mudanças no cenário da classe trabalhadora (ALENCAR, 2009) bem como nas suas condições de trabalho e de vida. Dessa forma, as empresas exigem um nível educacional mínimo, para certas funções, o que leva aqueles sem o grau de instrução adequado, a se deslocar e buscar atividades de menor qualificação profissional, com remuneração 
baixa e com a presença constante de instabilidade e geralmente em condições de trabalho precárias. Essas variáveis dentro desse contexto envolvem a saúde e a doença de um indivíduo ou população uma vez que ambas estão interligadas e são consequência dos mesmos fatores.

A relação direta entre trabalho e condições de saúde/doença das populações vem sendo estabelecida desde a antiguidade, existindo em certos períodos históricos a naturalização do trabalho (trabalho e vida cotidiana como estado intimamente relacionado) bem como de suas repercussões para a vida humana (SPIRANDELLI, 2009).

Para uma compreensão do que se refere ao trabalho dos catadores de materiais recicláveis, torna-se condição sine que non localizar, inicialmente, a realidade de vida e condições de trabalho em que se configura o público a ser estudado, tema de que trata o trabalho a ser desenvolvido na Cooperativa dos Agentes Autônomos de Reciclagem de Aracaju (CARE) localizada na periferia da capital sergipana no bairro Santa Maria.

Grupos populacionais que apresentam desigualdade possuem mais problemas de saúde bucal, independendo da riqueza da comunidade como um todo (CARVALHO et al 2009, ALENCAR 2009).

A condição bucal não se limita apenas a um registro quantitativo, mas também se relaciona diretamente com a história vivida de um grupo.

$\mathrm{Na}$ área de saúde bucal a pobreza e a exclusão sócio sanitária tem uma das suas mais evidentes manifestações, tendo em vista que pessoas pobres, que possuem baixa escolaridade e uma menor inserção no mercado de trabalho trazem consigo marcas dentárias que são reflexo de uma realidade objetiva e uma outra subjetiva (na grande maioria das vezes de forma velada) que ainda é pouco estudada nos seus aspectos básicos. (MEDEIROS \& MACEDO, 2007).

Esse quadro de saúde bucal desfavorável embasa ainda mais o estigma do portador do acometimento bucal e dessa forma potencializa sua exclusão.

Com relação a problemas bucais apesar de uma melhoria no quadro a nível mundial, ainda existe uma polarização de certos acometimentos nos grupos mais submetidos à privação social (CARVALHO, 2009). Assim, ao olhar para alguém e perceber dentes cariados, prótese desgastadaou fístula externa de abscesso (dentre outros) pode-se já identificar concepções que norteiam a forma pejorativa de se relacionar com este indivíduo (PORTO, 1999).

Tendo em vista o cenário apresentado, o estudo será direcionado para o cotidiano dos sujeitos que vivem da reciclagem do lixo, bem como suas condições de saúde bucal, tema esse que ainda é pouco trabalhado pela saúde pública brasileira.

A relevância do objeto de estudo está em colocar em pauta a importância de se conhecer os 
acometimentos de saúde bucal mais prevalentes neste grupo de trabalhadores, por sua própria ótica, bem como evidenciar a real necessidade de um acompanhamento e de intervenções, visando recuperar a saúde bucal dos mesmos, sugerindo a implantação de um programa integral em saúde bucal, temas relevantes para a saúde pública.

\section{ANTECEDENTES}

Os catadores de materiais recicláveis, com o intuito de organizar a categoria, se uniram em cooperativas e houve uma mobilização nacional para o reconhecimento formal da profissão, que ocorreu em 2002 (ALENCAR et. al 2009).

Segundo a Classificação Brasileira de Ocupações (CBO), se encontra a profissão "catador de material reciclável" sob o código 5192-05. Dentro das descrições das atividades do catador, feitas pela CBO: "catam, selecionam e vendem materiais recicláveis como papel, papelão e vidro, bem como materiais ferrosos e não ferrosos e outros materiais não reaproveitados".

A pesquisa foi realizada na Cooperativa dos Agentes Autônomos de Reciclagem de Aracajú (CARE) que foi instituída no âmbito do Projeto Lixo e Cidadania em Sergipe, coordenado pelo Ministério Público do Estado de Sergipe, em parceria com outros órgãos públicos e privados.

A criação da cooperativa teve como objetivo principal a inclusão social dos catadores de lixo, mediante a construção de uma unidade produtiva para o beneficiamento e comercialização de material reciclável, em condições mais dignas de trabalho, e de forma a proporcionar melhoria no nível de renda das famílias que desenvolviam atividades de catação na Lixeira da Terra Dura, localizada no Bairro Santa Maria, em Aracajú, SE.

Atualmente, a CARE conta com cerca de 80 membros, beneficiando 60 toneladas/mês de material reciclável proveniente de alguns bairros e conjuntos da grande Aracaju no sistema de coleta seletiva. Ao receber o lixo os cooperados da CARE separam o que poderá ser reciclado e, uma vez selecionado, o lixo processado é vendido, sempre buscando preços melhores do que aqueles oferecidos pelos intermediários. O resultado da venda é distribuído entre os associados de acordo com a produção de cada um.

Dentro da cooperativa não existe, atendimento odontológico regular. Quando existe a necessidade de um atendimento de urgência a opção é a unidade básica de saúde da comunidade, onde muitas vezes não conseguem marcação para o período que precisam ser atendidos para não perder horas de trabalho.

O fato da necessidade de trabalho ficar em primeiro lugar em comparação a necessidade de cuidar da saúde, seja bucal ou geral, leva a uma condição de considerar natural determinadas ocorrências em sua saúde, sendo que eles até percebem e citam a existência de fatores de risco, não reconhecendo, entretanto suas queixas ou problemas de saúde atuais como ocupacionais, sendo 
que os relacionam a outras questões, como idade e doenças prévias.

Dados como estes, apresentam grande semelhança, aos que foram encontrados em estudos sobre o mesmo grupo de trabalhadores por ALENCAR et al (2005), MEDEIROS et al (2007), PORTO (2004), SPIRANDELLI (2009) e OLIVEIRA (2011).

\section{OBJETIVOS}

\subsection{GERAL}

Descrever e analisar as condições de saúde bucal dos trabalhadores cooperados à CARE, evidenciando os acometimentos mais prevalentes e a opinião sobre tal situação por parte dos cooperados.

\subsection{ESPECÍFICOS}

1. Evidenciar os problemas odontológicos que são mais prevalentes;

2. Utilizando as informações adquiridas propor as bases para um projeto de acompanhamento odontológico para esse público e suas famílias.

\section{METODOLOGIA DA PESQUISA}

O autor da pesquisa entrou em contato com os dirigentes da Cooperativa e do Ministério Público Estadual em Sergipe (MP/SE), para solicitar permissão para realização da mesma, identificando os objetivos e colocando o termo de consentimento livre e esclarecido, TCLE (anexo 9.1) que foi dado para cada trabalhador, a fim de autorizar a tomada das informações previstas e poder definir os procedimentos mais adequados para os trabalhadores.

Uma vez autorizada, a pesquisa aceita para sua realização pelo comitê de ética em pesquisa, $\mathrm{CEP}$, foi realizada uma reunião com os participantes da cooperativa para explicar a pesquisa e sua importância para a busca de soluções a possíveis problemas de saúde geral e bucal que pudessem ser encontrados.

Apesar de múltiplas tentativas de comunicação com a maioria dos trabalhadores durante os dias de trabalho ocorreu que algumas instituições não priorizam conhecer a aproximação que há entre as condições mínimas de relação de trabalho com o processo de vida destes trabalhadores.

Foi necessário buscar, um dia possível para dialogar com algumas dessas pessoas a percepção que tem do cotidiano de trabalho.

Comoresultado desta situaçãonão foi possível detectar as principais necessidades epidemiológicas aceitando-se assim, a presença de dor como representante possível de sua condição de saúde bucal, 


\section{$216 / /$}

que poderia ser identificado sem a realização de um exame clínico efetivo.

Foi lamentável o descaso que algumas instituições tem por estes trabalhadores, na tentativa de esconder o que a sociedade vê, porém isso faz com que os mesmos, permaneçam a margem de uma efetiva solução do quadro atual.

\subsection{Procedimentos}

\section{a) Aspectos Éticos}

A pesquisa foi iniciada após a aprovação do CEP/UnB e após o aceite do orientador e da instituição envolvida, que por meio de sua representante no dia da pesquisa, concordou com a inclusão dos cooperados em participar da pesquisa (ANEXO A) e foram identificados por meio de uma ficha de identificação (ANEXO B).

\section{b) Local}

O presente projeto foi desenvolvido na Cooperativa dos Agentes Autônomos de Reciclagem de Aracaju (CARE) localizada na Rua A 5 Conjunto Gov. Antônio Carlos Valadares I, 150 Santa Maria, Aracaju-SE.

\section{c) Tipo de estudo}

Este estudo caracteriza-se por ser do tipo descritivo e analítico.

\section{d) População alvo}

A população alvo deste estudo foram cooperados da instituição que trabalham na coleta seletiva de materiais reciclados, sendo que no ato da pesquisa, apenas 12 aceitaram participar da pesquisa.

\section{e) Critérios de inclusão}

·trabalhadores Cooperados da CARE;

-ambos os sexos;

·todas as faixas etárias;

\section{f) Critérios de exclusão}

·trabalhadores de outros setores, não cooperados.

\section{g) Protocolo de avaliação}


A observação foi feita por meio de uma ficha de identificação com nome, idade e sexo. Em seguida os participantes responderam um questionário que trazia perguntas relacionados ao cotidiano dos mesmos, envolvendo temas relativos a sua rotina de trabalho, saúde geral e saúde odontológica. Esse questionário foi o norteador para avaliação do objeto dessa pesquisa e investiga aspectos distintos, a saber:

1 - Tempo trabalha na Cooperativa.

2 - Dias por semana trabalhados na cooperativa.

3 - Quando precisa de algum atendimento a saúde procura a Unidade de saúde da localidade?

4- Sentiu dor nos dentes nos últimos 04 meses?

5 - Em que lugar dói mais?

6- Procurou o posto de saúde ou foi procurar atendimento particular?

7 - Qual foi o motivo de sua escolha?

8- Essa dor de dente interferiu na sua alimentação?

9 - E no seu trabalho?

Os dados obtidos foram ordenados e analisados em quadros, para depois serem discutidos em relação a outros achados similares, desenvolvendo as conclusões pertinentes.

\section{RESULTADOS}

A CARE possui cerca de 80 cooperados, sendo este número variável de acordo com o acréscimo de novos trabalhadores a cooperativa.

Nessa pesquisa participaram 12 cooperados, sendo que no período da aplicação do questionário (um sábado) a maior parte dos cooperados não trabalha de forma habitual.

De acordo com a pesquisa, a distribuição com relação ao sexo foi de 09 indivíduos do sexo feminino com $75,0 \%$ e 03 do sexo masculino, com $25 \%$.

Conforme a tabela abaixo a idade foi distribuída da seguinte forma: $<=30$, de 31 a 40 anos, de 41 a 50 anos. Prevaleceu a idade $<=30$ com $50 \%$ e 25\% foi de 31 a 40 anos e de 41-50 anos. 
Porcentagem de idade dos cooperados participantes da pesquisa

\begin{tabular}{lc}
\hline IDADE & PORCENTAGEM \\
$<=30$ ANOS & $50 \%$ \\
$31-40$ & $25 \%$ \\
\hline $\mathbf{4 1 - 5 0}$ & $\mathbf{2 5 \%}$ \\
\hline
\end{tabular}

Fonte: Pesquisa do autor

Com relação a procura por atendimento médico, 09 dos participantes procuram a unidade com frequência com $75 \%$ e 03 esporadicamente com $25 \%$;

\section{Atendimento médico dos cooperados participantes da pesquisa: Frequência}

\begin{tabular}{lc}
\hline FREQUENCIA NA & PARTICIPANTES \\
PROCURA POR & \\
ATENDIMENTO & \\
Maior frequência & $75 \%$ \\
\hline Esporadicamente & $\mathbf{2 5 \%}$ \\
\hline
\end{tabular}

Fonte: Pesquisa do autor

No que diz respeito a sintomatologia dolorosa constante nos dentes 10 dos 12 cooperados incluídos na pesquisa, alegam sentir algum tipo de dor nos dentes nos últimos 4 meses com 83,3\% para o primeiro grupo e $16,6 \%$ para o segundo grupo pesquisado;

Dentro desse subgrupo, 08 indivíduos apontam a região posterior como a que mais provoca dor, com $80 \%$ e 02 indivíduos sofrem mais com a região anterior representando $20 \%$ da amostra.

Ainda nesse subgrupo 05 procuraram como atendimento principal o consultório particular, com $50 \%$, e 05 procuraram atendimento principal na unidade de saúde da localidade, representando os $50 \%$ restantes.

A dor apresentada independente da região é motivo de incomodo na alimentação de 08 , com $80 \%$ dos participantes, sendo que a mesma é tolerada por 02 participantes, com $20 \%$.

E essa sintomatologia, dentro desse grupo interfere em níveis variáveis o desempenho no seu trabalho. Não atrapalha 02, com 16,6\% Perda de concentração leve 04 com 33,3\%, desatenção constante 04 com $33,3 \%$ e incomodo extremo 02 , o que equivale a $16,6 \%$. 
Relação de sintomatologia dolorosa e interferência no trabalho dos cooperados participantes

\begin{tabular}{lc}
\hline INTERFERENCIA & PARTICIPANTES \\
NO TRABALHO & \\
Não atrapalha & $16,6 \%$ \\
Perda de & $33,3 \%$ \\
concentração leve & \\
D e s a t e n ç ã o & $33,3 \%$ \\
constante & \\
\hline Incomodo extremo & $\mathbf{1 6 , 6 \%}$ \\
\hline
\end{tabular}

Fonte: Pesquisa do autor

\section{DISCUSSÃO}

Os trabalhadores da reciclagem estão inseridos num ciclo econômico altamente rentável, mas não para eles. Apesar de desenvolverem uma atividade de grande relevância neste mercado específico, os catadores realizam seu trabalho num cenário que se caracteriza por uma ausência de proteção social colocando os mesmos em uma posição de risco tanto social como físico, o que tem grande influência em sua condição de saúde.

E inegável que no momento contemporâneo, a reciclagem de lixo vem se mostrando como uma novidade no universo de trabalho, o que por sua vez, gera uma atração cada vez maior de indivíduos para esse mercado.

O que chama a atenção junto a esse crescimento também é o risco multifacetado desde aquele perceptível (visível), como a insalubridade dos espaços onde se dá essa forma de trabalho, até aquele que é mais ignorado, e que se manifesta de forma velada como a violência, a indiferença e a intolerância da sociedade.

Partindo do ponto de vista de que o conceito de saúde ultrapassa a condição de ausência de doença, compreendida enquanto qualidade de vida e que contempla condições de vida, para este grupo populacional específico, estes aspectos são interferidos de forma negativa, tendo em vista o tipo de trabalho degradante que executam.

Além disso, essas pessoas vivem de uma forma geral sem ter acesso à saúde, escola, inserção social, lazer, saneamento básico, condições adequadas de moradia, direitos que deveriam lhes ser garantidos pela esfera de governo responsável, os catadores, diante dessa dura realidade, se voltam para alternativas para tentar transpor o estigma de marginalização que em muitos casos é atribuído a esse grupo, uma vez que nas ruas, recebem tratamento indigno a um trabalhador honesto.

ISSN 1982-8829 Tempus, actas de saúde colet, Brasília, 13(3), 211-223, set, 2019. Epub Ju1/2020 
A condição socioeconômica em que vivem os catadores de materiais recicláveis faz com que o objetivo primordial para eles, seja garantir sua sobrevivência e de suas famílias, deixando de lado possíveis riscos presentes no seu ambiente de trabalho, onde esses são apreendidos como um quinhão integrante do contexto desse trabalho e não, como poderia deliberadamente mostra-se, como consequência do mesmo.

Eles são milhares, que vivem na pele a exclusão social que é, por sua vez, tão abordada em discursos políticos, motivo de discussão entre intelectuais e/ou pessoas importantes da sociedade, mas que em termos práticos nunca tiveram um contato mais próximo com a realidade, além de suas salas fechadas com ar condicionado.

Dessa forma, para tentar romper com as relações sociais excludentes, que os colocam a margem social, uma alternativa viável para os mesmos vem se mostrando com o cooperativismo que navega na corrente da ajuda mútua não havendo, dessa forma a existência de concorrência e competição, buscando na sua gênese construir uma sociedade mais equitativa, democrática e estabelecida no pilar da sustentabilidade.

Segundo Veiga e Fonseca (2002), podemos definir uma cooperativa como sendo uma associação voluntária de no mínimo 20 pessoas, sem fins lucrativos, porém com fins econômicos, que exercem uma mesma atividade para realizar objetivos comuns, que para tanto contribuem equitativamente para a formação do capital necessário por meio da aquisição de quotas-partes e aceitam assumir de forma igualitária os riscos e benefícios do empreendimento. É regido pelo princípio democrático de cada pessoa um voto. Os excedentes ou sobras são distribuídos na proporção do trabalho de cada cooperado.

Em se tratando da atividade laboral, a sistematização dos trabalhadores da CARE atuando como cooperados da reciclagem resolveu alguns problemas, entretanto, trouxe ou manteve outros. A geração de renda sem dúvida representa parte da solução, uma garantia mínima para a própria sobrevivência e de suas famílias.

Os ganhos para os trabalhadores, tendo em vista o cenário que os mesmos estão inseridos foram, com certeza relevantes, uma vez que a informalidade e a pobreza são problemas que persistem e toda essa complexa rede interage com a saúde do sujeito, pois permeia várias dimensões do bemestar físico, psíquico e social (Rosa,Caircchioli e Bretas, 2005).

Com os dados obtidos após a aplicação do questionário, ficou evidente quemesmo que a intenção fosse evocar um agir preventivo, as respostas obtidas denotam claramente uma preocupação que mais se direcionada para se precaver do desconforto que uma sintomatologia dolorosa possa vir a causar, do que propriamente, vir a ter uma atenção de caráter preventivo integral no sentido do cuidado à saúde. 
Outra preocupação presente na fala dos trabalhadores se evidencia pelo fato de, como cooperados, os mesmos trabalham por produção, e sua jornada de trabalho é diária de segunda a sábado, no grupo participante, o que significa que uma ausência por motivo de doença, levaria há uma diminuição de proventos e consequentemente impactos no orçamento familiar, tão diminuto, mesmo no sistema de partição adotado na cooperativa.

Dessa forma uma procura por atendimento médico, se dá de forma esporádica na unidade de saúde, uma vez que, segundo o relato da maioria dos cooperados, chega durante a madrugada para pegar a ficha, e depois do atendimento, que é na mesma comunidade, conseguem voltar ao trabalho, resolvendo ou não, o motivo que os levou a procurar atendimento médico.

Quando se trata de morbidades de ordem odontológica, parece que por conta das características do trabalho e da necessidade de manutenção familiar, enquanto analgésicos se fazem eficazes no controle da dor, os mesmos não procuram atendimento odontológico. Mas a ocorrência de sintomatologia dolorosa dentária é frequente dentro do grupo participante. A busca por atendimento em consultórios particulares que oferecem preços populares chamou a atenção, pois os mesmos apresentam baixa renda e mesmo assim optam por sacrificar parte de seus proventos para obter um atendimento odontológico mais rápido e que não os faça ausentar-se do trabalho por longos períodos.

\section{CONSIDERAÇÕES FINAIS}

A profissão de catador de materiais recicláveis leva invariavelmente dentro do seu contexto, a existência de impactos à saúde e diretamente a qualidade de vida destes sujeitos, devido ao modo pelo qual os mesmos são inseridos no campo de trabalho, o que pode ser observado através desta aproximação a sua realidade.

A cada dia surgem novas cooperativas como a CARE, de separação de lixo reciclável, em inúmeras cidades, porém é notado que ainda se carece de forma efetiva de uma política social e de saúde que atenda as reais necessidades desse grupo expressivo de trabalhadores brasileiros.

A condição de saúde bucal fica vinculada a capacidade de tolerância à sintomatologia dolorosa, mesmo que venha a atrapalhar sua alimentação e consequentemente sua jornada de trabalho.

É de fundamental importância para os trabalhadores da saúde a compreensão da forma como é vista, pela ótica desses sujeitos, a sua condição de saúde.

Quando não se tem essa noção, ficou claro que os mesmos (os trabalhadores) acabam por diluir sua capacidade de indignação, o que culmina na omissão de seus próprios sentimentos, que parecem

ISSN 1982-8829 Tempus, actas de saúde colet, Brasília, 13(3), 211-223, set, 2019. Epub Jul/2020 
ser assimilados no seu cotidiano, vertendo-se para um estado de banalização da injustiça social.

É fato evidente, que o presente estudo feito na CARE, observando uma fração da rotina desses trabalhadores, dentro da sua realidade e segundo o seus relatos não deve encerrar-se em si devendo, por sua vez, provocar um novo olhar, com uma característica mais analítica e com uma sensibilidade a sua realidade para que os catadores de materiais recicláveis não vivam com o descaso, tendo em vista a rotina penosa que tem de enfrentar todos os dias, sacrificando pela sua subsistência, sua condição de saúde bucal e geral. É de interesse do pesquisador, prosseguir com a temática da pesquisa, uma vez que existem elementos dentro desse contexto, que também acabam tendo uma participação importante e decisiva na condição de saúde dessas pessoas.

\section{REFERÊNCIAS}

ALMEIDA, T.F: \& VIANA, M.I.P. O Papel da Epidemiologia no Planejamento das Ações de Saúde Bucal do Trabalhador, Saúde e Sociedade v.14, n.3, p.144-154, set/dez, 2005.

ALENCAR, M.C.B.; CARDOSO, C.C.O; \& ANTUNES, M. C. Condições de trabalho e sintomas relacionados à saúde de catadores de materiais recicláveis em Curitiba. Rev. Ter. Ocup. Univ. São Paulo, v. 20, n. 1, p. 36-42, jan/abr. 2009.

BREVIDELLI, M.M; \& DE DOMÊNICO, E. B. L. Trabalho de conclusão de curso: guia prático para docentes e alunos da área da saúde. 1. ed. São Paulo, 2006.

CARVALHO, E.S et al. Prevenção, promoção e recuperação da saúde bucal do trabalhador. RGO, Porto Alegre, v. 57, n.3, p. 345-349, jul/set. 2009.

MEDEIROS, L.F.R; \&. MÂCEDO, K.B. Profissão: catador de material reciclável, entre o viver e o sobreviver. G\&DR .v. 3, n. 2, p.72-94, mai/ago /2007.

OLIVEIRA, D. A. M. O48p Percepção de riscos ocupacionais em catadores de materiais recicláveis: Estudo em uma Cooperativa em Salvador-Bahia. / DeniseAlves Miranda de Oliveira. - Salvador, 2011. xiv, 174 f. ; il.

MEDEIROS, L.F.R.; \& MACEDO, K.B. "Catador de material reciclável: uma profissão para além da sobrevivência?” Psicologia \& Sociedade; 18 (2): 62-71; mai./ago, 2006.

PIZZATO, E.; GARBIN, C.A.S. Odontologia do trabalho: Implantação da atenção em saúde bucal do trabalhador. Odontologia. Clín.-Científ., Recife, 5 (2): 99-102, abr/jun., 2006. 
PORTO M.F.S et al. Lixo, trabalho e saúde: um estudo de caso com catadores em um aterro metropolitano no Rio de Janeiro, Brasil. Cad. Saúde Pública, Rio de Janeiro, 20(6):1503-1514, nov/dez, 2004.

RUDIO, F. V. Introdução ao projeto de pesquisa científica. 25.ed. Petrópolis: Vozes, 1999. $121 \mathrm{p}$.

Artigo apresentado em outubro de 2019 Artigo aprovado em janeiro de 2020 Artigo publicado em julho de 2020 